\title{
La Modernidad como Experiencia en América Latina ${ }^{1}$
}

\section{Carlos OSSANDON B.*}

\begin{abstract}
1. Algo parecía andar mal en América Latina a fines del siglo XIX e inicios del XX. Una cierta "conciencia de crisis" se puede apreciar incluso tempranamente dentro del propio mundo liberal: para el caso chileno es lo que ensefía el texto de Bernardo Subercaseaux sobre el "viejo" José Victorino Lastarria. La creencia que bastaba destruir los residuos estructurales y mentales coloniales para poner a América Latina en la senda del progreso, de la democracia y del bienestar económico -creencia que movilizó parte importante de las "energias" postindependentistas-, no parecía obvia a la luz de los problemas no resueltos por un proyecto "moderno-civilizador" que tomó distintas figuraciones. Nuevos y viejos problemas -en particular, esa "barbarie" negada por la conciencia liberal- volvian a aparecer, dificultando la realización de esas esperanzas o deseos (consultar al respecto las obras del mexicano Leopoldo Zea). En ciertos circulos letrados se constata entonces un esfuerzo por hacer un "recuento" y sobre todo "evaluar" los resultados de las expectativas y realidades abiertas por dicho proyecto.

"Ruines tiempos", señaló José Martí en 1882, en su Prólogo al Poema del Nidgara de Juan Antonio Pérez Bonalde. Lo repite tres veces, como para que no quede duda. En su diagnóstico, Martí capta lúcidamente el carácter insustancial, o "nihilista" podrámos decir, de una modernidad que no tiene
\end{abstract}

1 Conferencia dictada en las V Jornadas de Estudiantes de Postgrado en Humanidades, Artes y Ciencias Sociales: "Espacios de Transculturación en América Latina. Lugares, sujetos y prácticas". Universidad de Chile. 21 de enero de 2004. Este texto conserva las modalidades propias de una presentación oral y constituye una parte del marco histórico-cultural más general dentro del cual se inserta la investiga-
ción Fondecyt n. 1010016 .

* Profesor Instituto de la Comunicación e Imagen. Universidad de Chile. 
o no se sustenta en referentes estables y donde hasta "Dios anda confuso" $y$, ciertamente con mayor razón, los escritores o poetas, quienes en "esta revuelta vida sin vía fija" no sólo quedan privados de esas "luengas y pacientes obras" de antańo sino también, agregamos, de esas "auras" que envolvieron el período de la fundación republicana.

Como si la experiencia del "desencanto" o incluso del "vacío" se instalasen quizá por primera vez en América Latina. Experiencia perceptible en las creaciones del chileno Pedro Antonio González, aunque más nítidamente aún en el poema Lo fatal de Rubén Dario, en esa "desolación absurda" del uruguayo Julio Herrera y Reissig (él mismo, se podría decir, "enfermo de absintio verde") o en esa "sombra densa" o en ese "tedio profundo" del cubano Julián del Casal confesados en su poema Nihilismo. Como si se advirtiese ya esa crisis de fundamentos que comienza a afectar a una sociedad en acelerada mutación, descubriendo, como dirá Jean-François Lyotard muchos años después, "lo poco de realidad que tiene la realidad".

Para ciertos escritores la modernidad ha dejado de ser "construcción" o "proyecto", ahora es más bien "experiencia", "vivencia", "desencuentro" personal. La modernidad se "subjetiviza", interpela directamente, afecta vocaciones, núcleos subjetivos. La "ciudad" -como se ha sefialado en otro estudio- ya no es más ese espacio utópico que concentra todas las aspiraciones del proyecto moderno-civilizador, tan nítido en autores como Domingo Faustino Sarmiento o Juan Bautista Alberdi, y pasa a ser tráfico, vallas rotas y también desasosiego, incertidumbre o ese "impuro amor" que parece profesar el ya citado Julián del Casal. O una mezcla de tradición y novedad, de espectáculo y sensualidad, tal como se aprecia en esas crónicas que Rubén Darío redactó para El Mercurio de Valparaíso a propósito de la Exposición Mundial de París en 1900. O un complejo laberinto que sólo la prensa diaria logra "mapear" o fijar sus tiempos, espacios o servicios.

Por otra parte, ciertos textos exhiben un lenguaje clínico, no optimista, que también arroja luces respecto de las nuevas percepciones del periodo que examinamos. En 1899 se publica El Continente enfermo del venezolano César Zumeta, en 1909 se publica Pueblo enfermo del boliviano Alcides Arguedas, entre otros títulos semejantes. En esta línea, que combina el lenguaje clínico o biológico, o más genéricamente el positivismo, con la crítica social radical, son suficientemente reveladoras esas diversas "autopsias" que realiza el "doctor" Valdés Cange en su conocido Sinceridad. Chile intimo en 1910.

2. Nuevos "fantasmas" o temores emergen en el teatro social, que repercuten en los escritores. La irrupción de las "muchedumbres" y del "mercado" tan agudamente captado por los "modernistas" finiseculares; la irrupción más especificamente de nuevos "actores" sociales (estudiantes, indios, 
jóvenes) y que autores como Julio Antonio Mella, Manuel González Prada, José Carlos Mariátegui o José Enrique Rodó se encargarán de resaltar. La irrupción, en otro orden de cosas, de los nuevos códigos de la imagen en diarios, revistas magazinescas, en el cine mudo; y también de esos productos seriados no "auráticos" de las nacientes industrias culturales. La manifestación, ahora más visible, de esos lados oscuros, inconfensables, "siniestros" (no exteriores sino internos) de la modernidad: las desigualdades, las miserias, los hacinamientos. Como vemos, las inquietantes nuevas realidades se despliegan en distintas direcciones. Se confunden también con los afanes totalizadores de la ciencia y del progreso, que no parecen respetar los fueros más subjetivos y dispersos de las letras. Rubén Darfo piensa en este sentido que las máquinas expulsan a las musas y apagan el eco de las liras.

En el plano cultural, Pedro Henríquez Urefia constata una progresiva (desigual e incompleta, habría que afiadir) fragmentación -una "división del trabajo", dice- que viene a disolver, o a relativizar al menos, antiguas estrategias de legitimación literaria y a desplazar a ese "intelectual" (una voz inapropiada para el siglo XIX) que, como examina Julio Ramos, habla establecido una intrincada o compleja relación entre letras y proyecto modernizador. En un sentido distinto al horizonte que dibujó Andrés Bello en su célebre Discurso de Inauguración de la Universidad de Chile, ahora las "verdades" ya no siempre se tocan, comienzan a separarse más bien.

Los nuevos "fantasmas" o temores no son ajenos a unos desplazamientos culturales que dejan en mal pie a ciertos reductos más exclusivos (a esa "espiritualidad" o "humanismo" reivindicados por el Ariel de Rodó); tienen que ver también con las nuevas "figuras" que se imponen en los espacios públicos (el "artista" y sobre todo la "estrella" cinematográfica y el "ídolo" deportivo hacen su estreno en las primeras décadas del $\mathrm{XX}$ ) por encima de aquellos "rostros" letrados característicos del XIX; se confunden con los nuevos "gustos" e "inclinaciones" que se comienzan a imponer por sobre otros dispositivos más "raciocinantes" o "argumentales"; con el desarrollo asimismo de unas matrices culturales (sensacionalistas o melodramáticas) estimuladas por la prensa; con la flexibilización de la brecha entre lectura y escritura; con la segmentación del ámbito de los intereses públicos; con nuevos modos de recepción y de lectura (ahora más "extensivos" que "intensivos"); con -en fin- las nuevas condiciones que comienzan a articular el propio proceso creativo o cultural global.

Nuevamente es José Martí quien con mucha lucidez capta la imbricación que se da entre los nuevos escenarios y estos procesos. Subrayando el carácter profundamente heracliteano y perturbador de la modernidad, destaca el "desmembramiento de la mente humana", el carácter colectivo y no indi- 
vidual de la cultura, el tráfico de las ideas, los nuevos ritmos e intensidades del pensamiento, la extensión y resignificación que experimenta el campo de la estética. En los nuevos escenarios, dice Marti, "ha entrado a ser lo bello dominio de todos", con la consiguiente alarma que estos cambios o posibilidades provocan en los bardos o letrados tradicionales, sin excluir a los llamados "nuevos" por Armando Donoso. Cabría preguntarse en suma si, en la percepción de ciertos escritores, no es la cultura ilustrada o letrada clásica la que es puesta en entredicho como resultado de unas transformaciones culturales no menores, que afectan formatos, narraciones, estrategias de lecturas, sensibilidades, nuevos modos de relación entre las esferas pública y privada, etc. Dicho en términos habermasianos, se podria decir que lo que estos escritores captan, suscitando unas reacciones no siempre nítidas (algo duales o ambiguas), es el paso o la transformación del espacio público ilustrado y su reemplazo por otro masivo, ligado al consumo y al despliegue de nuevas percepciones y dispositivos comunicacionales. Como se sabe dicho paso tuvo para Habermas el sentido de una "regresión", de un viraje a la "minoría de edad" pre-ilustrada, de una vuelta a unos espacios más "semiológicos", poblados de "marcas" o "gestos". La impresión que se viven nuevos tiempos ronda ciertamente en la cabeza de los escritores que hemos venido citando, cuestión que se hace particularmente visible en los "hijos de Rubén Dario".

3. Los nuevos diagnósticos o evaluaciones no se reducen, a pesar de lo dicho, a mera "negatividad". Para Martí, una vez más, es ésta una época llena de "tumulto y dolores", pero también "de elaboración y transformación espléndidas", donde "todo es expansión, comunicación, florescencia, contagio, esparcimiento". Esta época da cuenta de un pathos faústico, alucinante, pero que demuele sin piedad, expulsa a los dioses pero instala nuevas hegemonías, "en particular a unos "gigantes que llevan siete leguas en las botas" dirá Martí, a ese "invasor de la América ingenua", según la conocida Oda $A$ Roosevelt, de Darío. Estos diagnósticos exigirán la búsqueda de nuevos entramados discursivos y también otros "posicionamientos" para el escritor. En la línea examinada por Julio Ramos, cabe preguntarse respecto de las nuevas formas de legitimación que se podian ensayar en el contexto de una sociedad en crisis, que hacía ostensibles ciertos cambios en las relaciones entre un "campo cultural" cada vez más consciente de sí y los nuevos poderes, sin ahora los viejos patrocinadores del trabajo intelectual o sin unas imago mundi que habían permitido ciertos consensos o referentes básicos. La pregunta parece pertinente en la medida que las nuevas condiciones, y el mercado en especial, ya no portaban las antiguas "garantías" (o más bien por definición no tráan garantía alguna), aunque no por ello se podía renunciar a continuar escribiendo $o$ a imaginar mundos. 
La evaluaciones o balances, así como las nuevas condiciones del capitalismo dependiente, no sólo llevarán a reexaminar el "lugar" del escritor, a fijar sobre sí la atención, sobre su "autonomfa" (cuestión que permitirá por lo demás importantes rendimientos creativos); estas revisiones exigirán simultáneamente la búsqueda de nuevos "lentes". Volvamos a citar a Marti. En el texto $E l$ cardcter de la Revista venezolana de 1881 -texto que ha sido considerado como el primer manifiesto del "modernismo" literario hispanoamericano-, el autor cubano sefiala que vivimos "en una época de incubación y de rebrote, en que, perdidos los antiguos quicios, andamos como a tientas en busca de los nuevos". En este contexto surgen nuevas visiones que a ratos tienen la ambición de ser algo más que ideas nuevas o manifestación de "experiencias", en la medida que se ofrecen antes bien como "ordenes mentales", como nuevos mapas cognitivos y políticos. Al respecto, se podŕa citar el esteticismo y latinismo de José Enrique Rodó que busca establecer un nítido contraste con la cultura norteamericana, encarnación esta del verbo utilitario; la resignificación y síntesis de las polaridades sarmientinas ("civilización" o "barbarie") en Ricardo Rojas con su Blasón de Plata o Eurindia, la revisión de la propia "episteme" o dualismo sarmientino en el ya citado Marti, quien propondrá ya no contraponer sino "hermanar" la "vincha" con la "toga"; el marxismo -en fin- no meramente divulgador sino interventor y lector de Los siete ensayos, de Mariátegui, que busca ensamblar las nuevas "categorías" con la "realidad" del Perú, apostando a una suerte de síntesis epistemológica entre lo universal y lo particular. En Chile, habría que mencionar en esta dirección al ya citado doctor Valdés Cange (seudónimo de Alejandro Venegas) que exhibirá un instrumental analítico algo desusado para la época y que anuncia ya los modernos métodos sociológicos; la activación de un ensayismo nuevo, crítico, en torno al Centenario, que denuncia el despilfarro y la crisis moral oligárquica, el llamado "modo de ser aristocrático"; la impronta de los "vitalismos" (pensemos en la influencia de Bergson en Enrique Molina, uno de los llamados "fundadores" de la filosofla en Hispanoamérica) que intentarán reemplazar el positivismo decimonónico; la conferencia Ricos y pobres, de Luis Emilio Recabarren, que propondrá una nueva articulación y balance de los cien años de vida republicana y, sobre todo, un distinto modo de mirar la sociedad; los experimentos tolstoyanos a comienzos del XXo las nuevas voces que comienzan a manifestar las mujeres en los escenarios públicos.

En este conflictivo y rico escenario, quedarán planteadas algunas tensiones o perspectivas que pudiesen dialogar con nuestro presente. Algunos dicen que los fines o comienzos de siglo suelen parecerse. Es difícil saberlo. Con más seguridad se puede afirmar que la mirada histórica es un modo más de entender el presente, por de pronto a partir de sus ausencias o resi- 


\section{COMUNICACION y MEDIOS}

duos; que la posibilidad de hacer operar ciertas tensiones pasadas, ya idas, en los escenarios de su ausencia, es decir en el presente, pudiera arrojar algunos resultados (sin duda referenciales y mentales) en la propia comprensión de este presente. La incrustación del pasado en la escena de su ausencia como un modo de entender nuestros actuales "ruines tiempos" está lejos, sin embargo, de los propósitos o posibilidades de este expositor.

\section{Bibliograffa general:}

Andrés Bello: "Discurso pronunciado en la instalación de la Universidad de Chile", en Antologia de Andrés Bello. Zig-Zag, Chile, 1965.

Del neoclasicismo al modernismo. Historia de la literatura bispanoamericana. Tomo II. Luis Ińigo Madrigal (coordinador). Cátedra, Madrid, 1987.

Jürgen Habermas: Historia y crttica de la opinión pública. G. Cili, Barcelona, 1994. Pedro Henríquez Urefia: Las corrientes literarias en la América Hispanica. F.C.E., Colombia, 1994.

José Carlos Mariátegui: Siete ensayos de interpretación de la realidad peruana. Editorial Crítica, Barcelona, 1976.

José Martí: Obras Completas. Vol. 7. Editorial Nacional de Cuba, La Habana, 1963.

Graciela Montaldo: La sensibilidad amenazada. Beatriz Viterbo Editora, Argentina, 1994.

El modernismo en América. Antología de Horacio J. Becco. Edicom, Argentina, 1969.

Julio Ramos: Desencuentros de la modernidad en América Latina. Literatura y politica en el siglo XIX. Fondo de Cultura Económica, México, 1989.

Domingo Faustino Sarmiento: Facundo. Biblioteca Ayacucho, Venezuela, 1977. José Enrique Rodo: Ariel. Ed. Porrúa, México, 1968.

Martín Stabb: En busca de una identidad. Monte Ávila Editores, Venezuela, 1969.

Bernardo Subercaseaux: Fin de siglo. La época de Balmaceda. Ed. Aconcagua, Santiago, 1988.

Bernardo Subercaseaux: Cultura y sociedad liberal en el siglo XIX. Lastarria, ideologia y literatura. Ed. Aconcagua, Santiago, 1981.

138 | Guillermo Sunkel: Razón y pasión en la prensa popular. Ediciones Ilet, Santiago, 1985.

Dr. J. Valdés Cange (Alejandro Venegas): Sinceridad. Chile intimo en 1910. Ediciones Cesoc, Chile, 1998.

Leopoldo Zea: El pensamiento latinoamericano. Ed. Ariel, México, 1976. Leopoldo Zea: Precursores del pensamiento latinoamericano contempordneo. Sep Diana, México, 1979. 